\title{
Synthesis of carbon nanotubes by CVD over Fe catalyst prepared in spin coating on $\mathrm{SiO}_{2} / \mathrm{p}-\mathrm{Si}(100)$
}

\author{
Ahmed N. Abd \\ Department of physics, college of Science, University of Al-Mustansiriyah. Baghdad-Iraq \\ Email address: ahmed_naji_abd@yahoo.com
}

Keywords: carbon nanotubes, chemical vapor deposition, and catalyst effect.

\begin{abstract}
Carbon nanotubes (CNTs) have been grown by the decomposition of $\mathrm{C}_{2} \mathrm{H}_{2}$ over thin catalyst film in order to investigate the growth mechanism of CNTs by chemical vapor deposition (CVD). The catalyst was prepared from an iron chloride $\mathrm{FeCl}_{3}$ precursor solution that was spin coated on $\mathrm{SiO}_{2}$ substrate. The growth mechanism and the length and the diameter of the CNTs were greatly influenced by the precursor concentration, the time deposition and the temperature and the ratio of $\mathrm{C}_{2} \mathrm{H}_{2}: \mathrm{N}_{2}$ are fixed. Transmittance electron microscopy and Scanning electron microscopy and Raman spectroscopy and X-ray diffraction have been carried out in order to investigate the behavior of the growth process. The iron chloride film contact with the $\mathrm{C}_{2} \mathrm{H}_{2}: \mathrm{N}_{2}$ reaction atmosphere.
\end{abstract}

\section{INTRODUCTION}

Synthesis of carbon nanotubes (CNTs) has been extensively investigated by a number of research groups, since the first observation in 1991 [1], Carbon nanotubes (CNTs) have been studied intensively due to their importance as building blocks in nanotechnology since they were discovered. Their special geometry and unique properties offer great potential applications, including nanoelectronic transistors [2], energy storage [3], field emission devices [4], gas sensors [5],CNTs show great promise for future electronic applications, [6], CNTs are expected to find applications in all industrial areas, also provide rich research subjects. CNTs can be produced by different techniques; among them most widely used ones are arc- discharge [7], laser ablation [8], and chemical vapor deposition (CVD) [9]. We chose chemical vapor deposition (CVD) technique which has some distinct advantages over other techniques. The CNTs can grow at relatively low temperature, and the size of CNT can be controlled by varying the size of the metal catalyst. Furthermore, it is relatively easy to obtain vertically aligned CNTs. However, the process parameter control for the growth of CNT still remains in an empirical manner, because the reaction kinetics and the growth mechanism are not fully understood. Behavior of CNT in CVD process can be compared with that of the carbon filaments [10].

\section{EXPERIMENTAL}

\section{1. Description of the CVD apparatus}

The CVD apparatus used in our experiments is basically composed of a quartz glass tube with diameter $3.5 \mathrm{~cm}$, and tube furnace with diameter $4.5 \mathrm{~cm}$ and bulbar show in fig. 1 


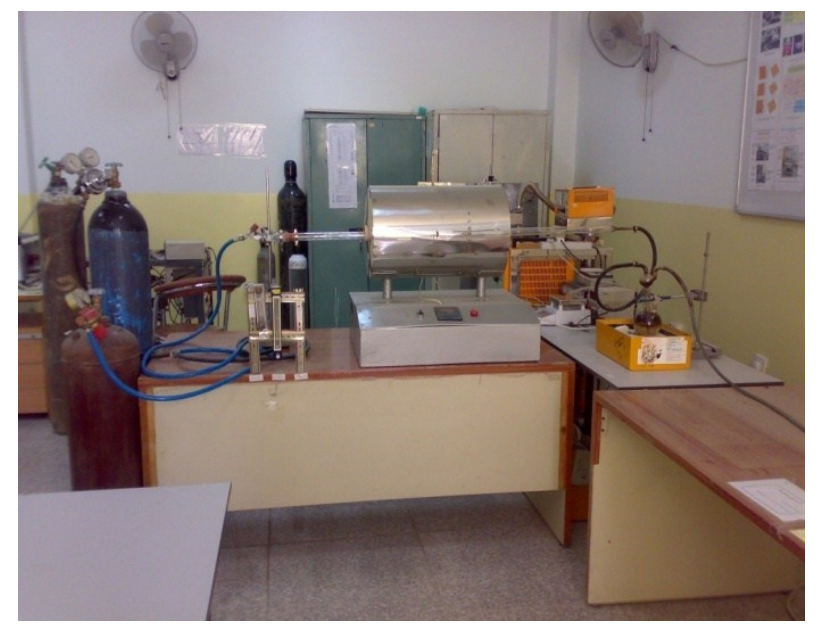

Figure 1: Photograph of setup CVD.

\subsection{Synthesis of nanotubes}

\section{The deposition of nanotubes was carried out in four steps:}

a. Silicon $(1 \times 1 \times 0.05) \mathrm{cm}$ substrate $(100) / \mathrm{p}$-type with resistivity of $15(\Omega . \mathrm{cm})$ was used. The substrate was cleaned in acetone 99.99 purity $100 \mathrm{ml}$ inside and put in the digital ultrasonic at $40{ }^{0} \mathrm{C}$ for 10 min with deionised water, ultrasonic with alcohol 99.99 purity for $5 \mathrm{~min}$,washing with deionised water , last step substrate were then dried with dry nitrogen. After cleaning substrate put it into a reactor, we have allowed the temperature increase to about $900{ }^{0} \mathrm{C}$, for removing again the remaining dirtiness. In this stage we inject pure oxygen in reactor for about $20 \mathrm{~min}$, Later we turn off furnace and cooling the substrate. The thickness of the $\mathrm{SiO}_{2}$ layer was estimated at approximately $300 \mathrm{~nm}$.

b. Preparation the catalyst nanoparticles we used spin coating method to deposition films on the silicon substrate. Solutions of concentration $(15,30,45,60,75$ and 90$) \mathrm{mM}$ were sonicated for 30 min before placed onto substrate. It was found that $\mathrm{FeCl}_{3}$ has better solubility in ethanol. The solution was dropped on $\mathrm{p}-\mathrm{Si}(100) / \mathrm{SiO}_{2}$ substrate in number of circular $1000 \mathrm{r} / \mathrm{min}$ for each once with spin coater at room temperature. The thickness of the deposited films can be changed with varying concentrations of $\mathrm{FeCl}_{3}$.

c. The coated substrate was carried out into quartz tube and introduces $\mathrm{N}_{2}$ high purity 99.99 with flow rate $85 \mathrm{sccm}$ in tube after this heating the tube with heat rate $20^{\circ} \mathrm{C} / \mathrm{min}$ until to reach the final temperature at $750{ }^{\circ} \mathrm{C}$. Stay in this temperature $30 \mathrm{~min}$ to forming Iron oxide clusters.

$\mathrm{d}$. The synthesis of nanotubes was performed by adding a constant flow rate of acetylene $(15 \mathrm{sccm})$ to the nitrogen carrier gas during $15 \mathrm{~min}$. After this step the acetylene switch off and the $\mathrm{N}_{2}$ continuously in flow until to cooling in room temperature.

\section{RESULTS AND DISCUSSION}

The images of AFM in fig. (2) Show a good coverage of catalyst on $\mathrm{P} / 100 / \mathrm{SiO}_{2}$ and an obvious dependence of size and density of nanoparticles on the surface. The average roughness and the average grain size is increase with increase concentration of the solution. The average roughness increase that beginning from $0.039 \mathrm{~nm}$ and end in $4.11 \mathrm{~nm}$ and average grain size beginning from $4.37 \mathrm{~nm}$ and end in $8.28 \mathrm{~nm}$ for $(15-90) \mathrm{mM}$. This must mean that there are some other parameters that are important in the dispersion. The distribution of clusters is strongly dependent on the type of salt, support and the distance from the center of the support to the edge [11]. The most obvious is the quantity of liquid dropped on the surface which will affect the quantity of iron molecules per unit area. 

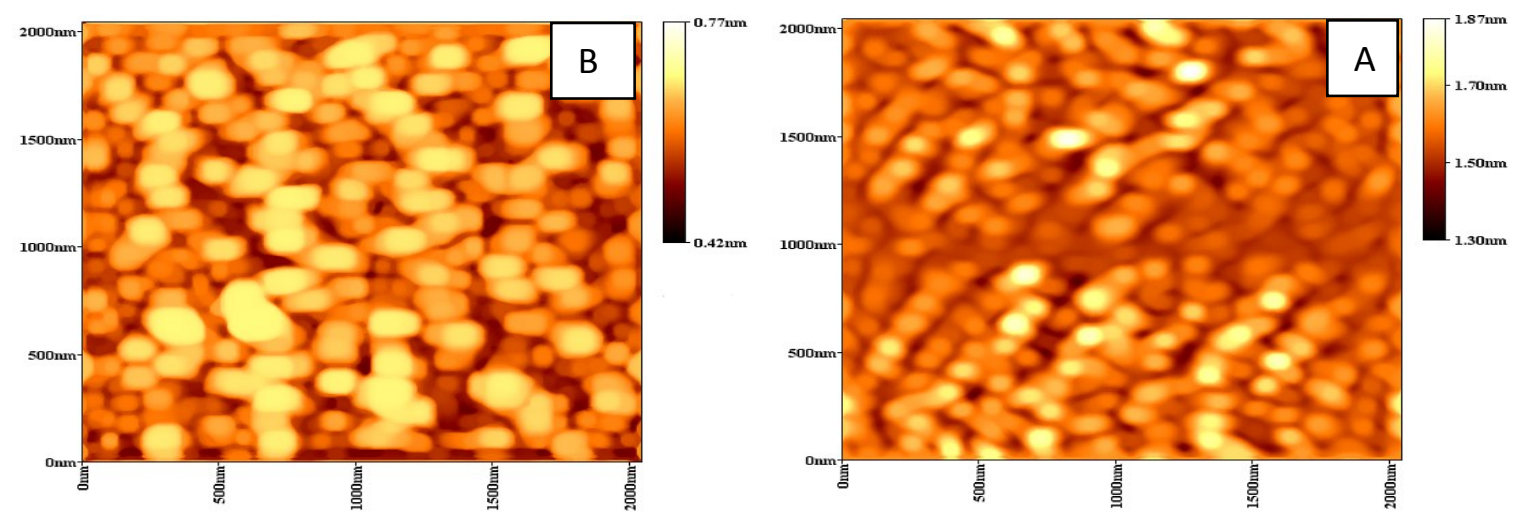

Figure 2: Show the catalyst at concentration A. $15 \mathrm{mM}$ and B. $30 \mathrm{mM}$.

Figure 3: Show SEM images of CNTs grown on the catalyst particles formed on the $\mathrm{p}(100) / \mathrm{SiO}_{2}$. We show that the nanotubes are oriented perpendicularly and helical shapes on the substrate surface for high densities of nucleation centers. A high nanotube density can be achieved with a high density of iron oxide clusters that are nucleation centers for the growth of nanotubes. The nanotubes synthesized by this method have diameters about between 20 and $80 \mathrm{~nm}$. The highest nanotube densities and film thicknesses of about $50 \mu \mathrm{m}$ were observed with the lowest iron chloride concentration at high temperatures $750^{\circ} \mathrm{C}[12]$.
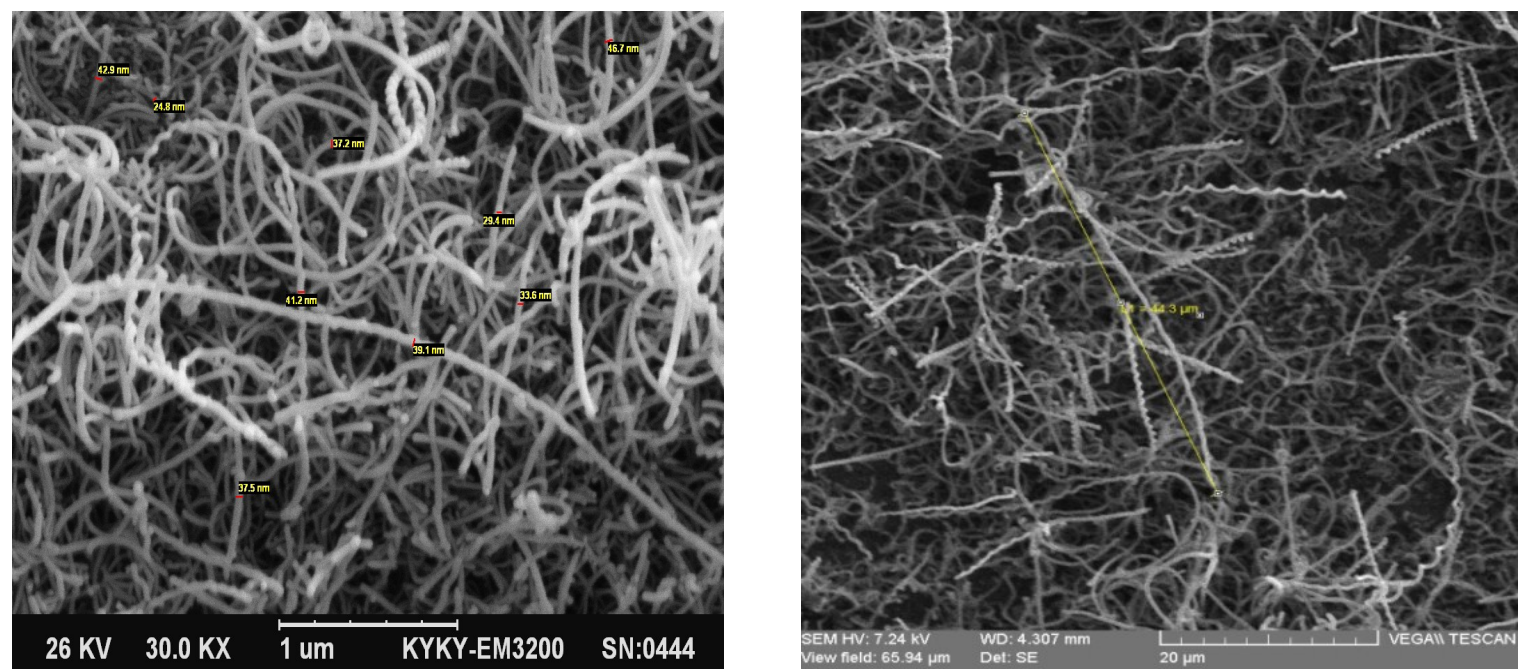

Figure 3: Show the growth of CNTs.

The TEM images shown in Figure 4 confirmed that the carbon structures were multiwalled carbon nanotubes, which hollow cavity, diameter about $80 \mathrm{~nm}$, and revealed the presence of iron particles mainly in the tip of MWCNTs, suggesting that a tip-growth mechanism might be predominant. The CNTs were not complete graphitization of the walls visible in the TEM imaged the presence of small amounts of amorphous carbon was confirmed by Raman spectroscopy and XRD analysis. The layers of CNTs, which are not clear separated probably caused by more defective growth [13]. Temperature annealing, up to $2200^{\circ} \mathrm{C}$, has demonstrated benefits on mechanical and physical properties. These treatments are increasing in the crystallite size, corresponding to an increase in the graphitic domains. Some prior literature exists in high temperature heat treatment of nanotube-like materials described the graphilization of entangled, sinuous nanotubes at $2800^{\circ} \mathrm{C}$ [14]. 

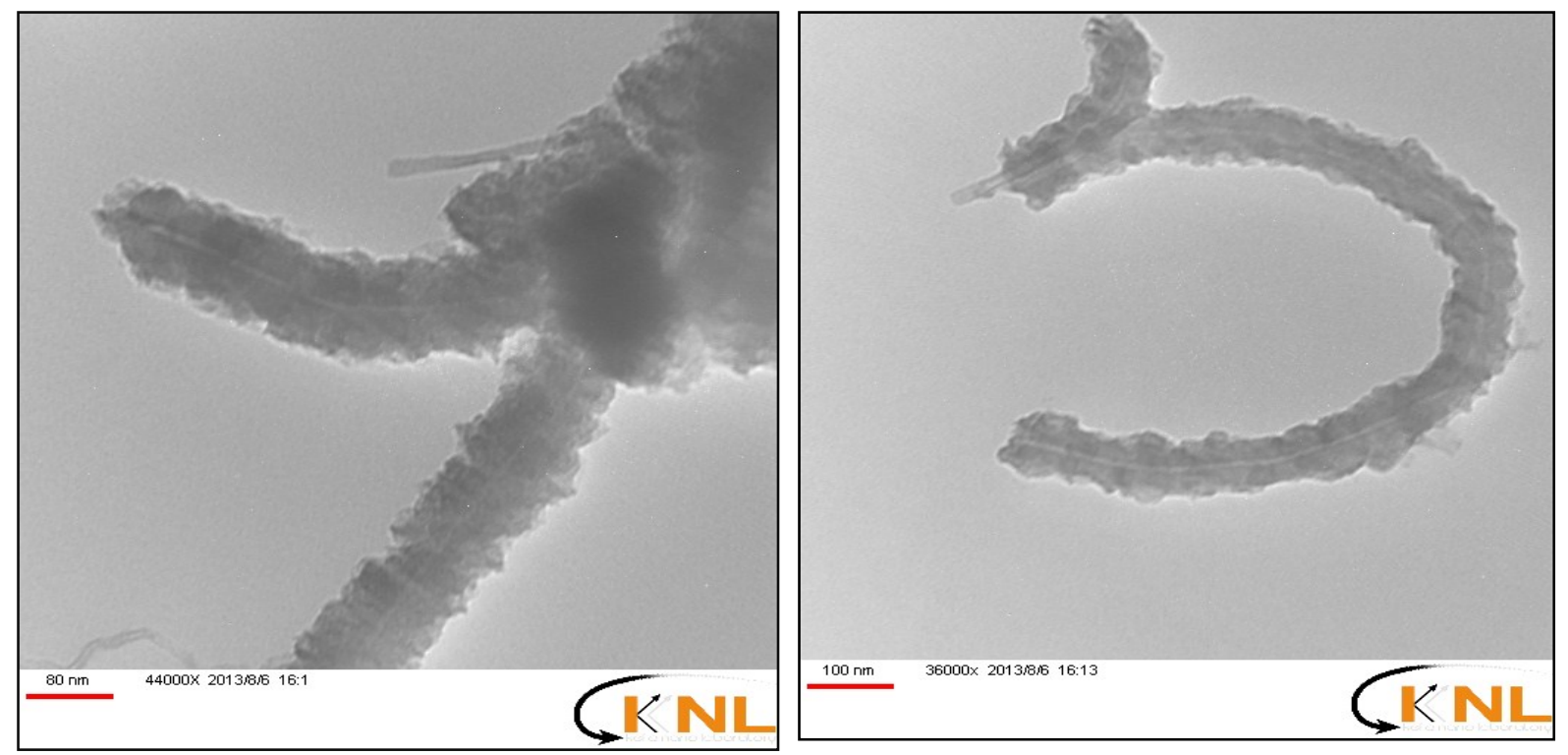

Figure 4: TEM images for MWCNTs.

An XRD measurement ( $2 \Theta$ scan) was carried out using $\mathrm{Cu} \mathrm{K} \alpha$ radiation to examine the structure of the CNTs. Fig5.A. show three clear characteristic peaks of the graphite structure in MWNTs at $26.2^{\circ}, 43.6^{\circ}$ and $50.7^{\circ}[15]$. Two graphite peaks corresponding to the $(002)$ and (100) planes at $2 \theta=$ $25.8^{\circ}, 43.5^{\circ}$ can be clearly seen and the broad diffraction peak of $(002)$ graphite planes at $2 \theta=25^{\circ}$ gradually increases with increasing annealing temperature [16]. Fig 5.B. show the wider peak of 002 centered at $24.97^{\circ}$ is induced by the disordered carbon and indicates to presence defect level in the atomic carbon structure. The significant diffraction pattern of the MWCNTs non pure function is appearing at and near $2 \theta$ of $25.3^{\circ}$ [17]. The peaks at $43.2^{\circ}$ for 100 plane indication of the low quality of carbon nano materials [18]. The peaks at $52.53^{\circ}, 54.16^{\circ}$, and $55.36^{\circ}$ are not originated from the CNTs. It should be noted that the peaks between $2 \Theta=50^{\circ}$ and $60^{\circ}$ are from the $\mathrm{Si}$ substrate [18]. The crystalline size of CNTs estimated from an $\mathrm{X}$ - ray diffraction peak using Scherrer's equation $(d=0.9 \lambda / B \cos \theta)$ where $d$ is the size of crystals, $B$ is the full width at half maximum of a peak in radians at the diffraction angle $\Theta$ and $\lambda$ is the $X$-ray wavelength, which is $\approx$ $0.15418 \mathrm{~nm}$ in this study $(\mathrm{CuK} \alpha)[18]$.
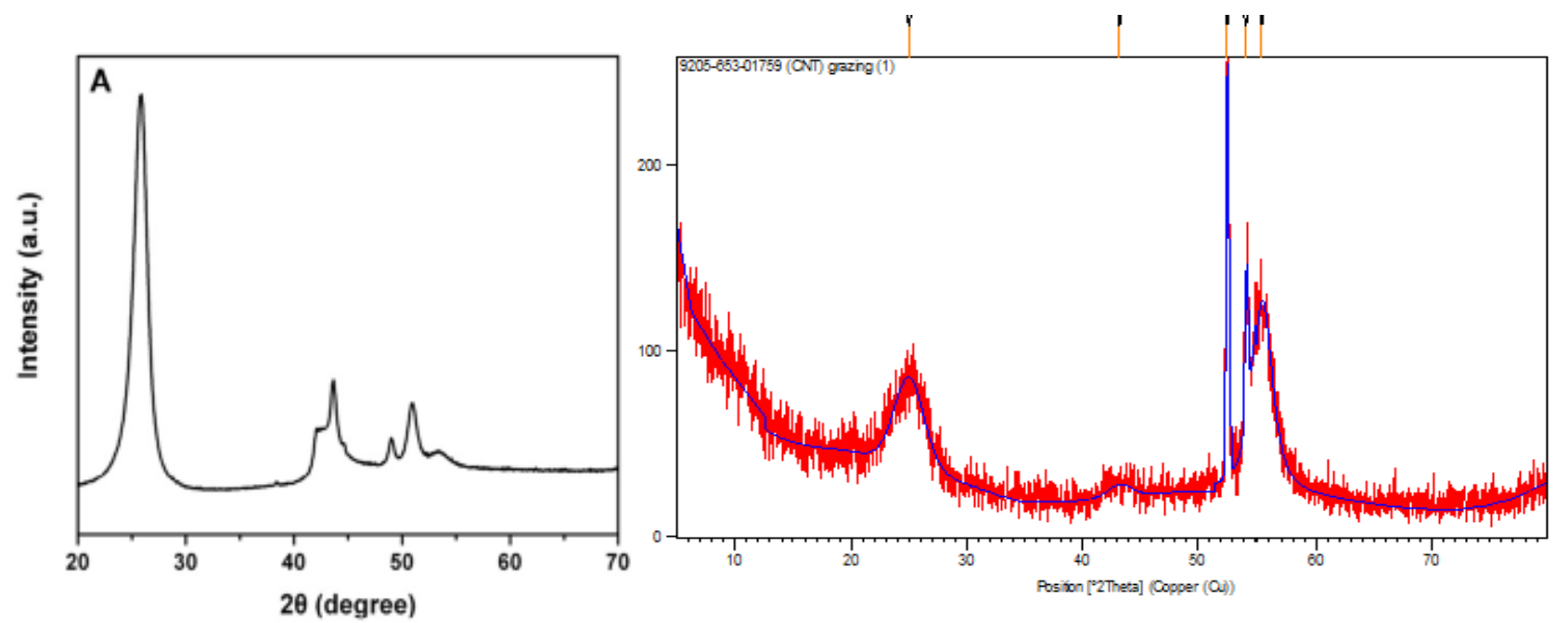

Figure 5: XRD spectra of A: typical MWNTs and B: p(100)/ $\mathrm{SiO}_{2}$ MWCNTs.

The Raman spectra of MWCNTs were non-functionalised are shown in Figure 6. The spectrum of carbon structure contains two main bands: the G-band $\left(1596 \mathrm{~cm}^{-1} \mathrm{MWCNT}\right)$, which is assigned to the $\mathrm{E}_{2 \mathrm{~g}} \mathrm{C}-\mathrm{C}\left(\mathrm{sp}^{2}\right.$ - bonded) stretching mode of a well-ordered graphitic structure and the D-band 
(1306 $\mathrm{cm}^{-1}$ for MWCNT), attributed to the $\mathrm{A}_{1 \mathrm{~g}}\left(\mathrm{sp}^{3}\right.$-bonded) stretching mode, resulting from the presence of a disordered structure or lattice defects in the graphite structure (substitutional hetero-atoms, vacancies or chemically bonded hetero-atoms). The bands at $2604 \mathrm{~cm}^{-1}$ (G' band) for MWCNTs constitute an overtone of the D band. Due to such a highly defective MWCNT structure. At the second order mode observed between $2604 \mathrm{~cm}^{-1}$ assigned to the first overtone of the D mode (2D) and often called G' mode, which is highly dispersive. The G'-band feature (operative for the graphite) is based on double resonance mechanism. The D-band and G'-band show, for graphite or nanotubes, a strong dispersion as a function of laser excitation energy (their frequency are sensitive to the excitation wavelength), while the G-band is not dispersive. The peak $454 \mathrm{~cm}^{-1}$ and the broad peaks around (300-700) $\mathrm{cm}^{-1}$ belong for $\mathrm{Fe}_{2} \mathrm{O}_{3}$ and other types of iron oxide nanoparticles.

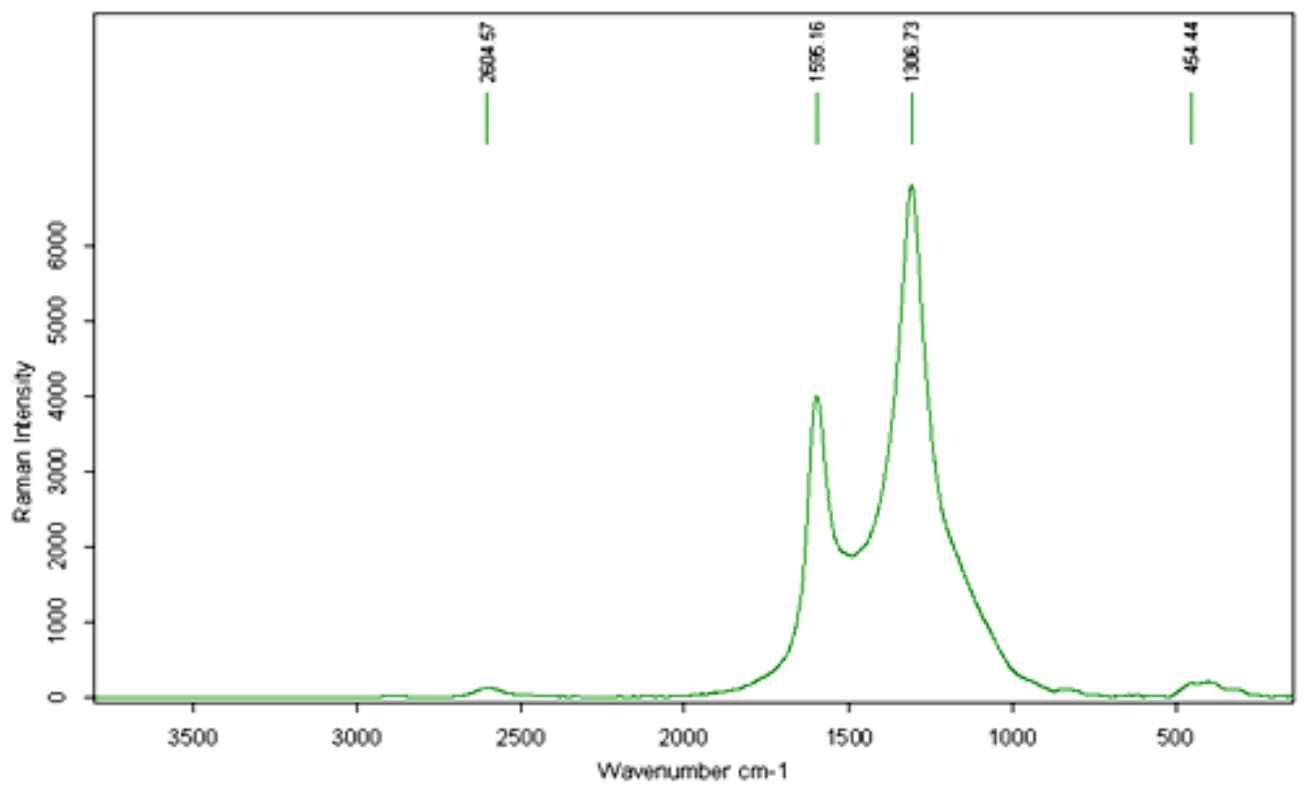

Figure 6: Raman spectrum of MWCNT/ $\mathrm{Fe}_{2} \mathrm{O}_{3}$ nanostructure.

At second order mode observed between $2604 \mathrm{~cm}^{-1}$ assigned to the first overtone of the D mode (2D) and often called G' mode, which is highly dispersive. The G'-band feature (operative for the graphite) is based on double resonance mechanism. The D-band and G'-band show, for graphite or nanotubes, a strong dispersion as a function of laser excitation energy (their frequency are sensitive to the excitation wavelength), while the G-band is not dispersive. The peak $454 \mathrm{~cm}^{-1}$ and the broad peaks around (300-700) $\mathrm{cm}^{-1}$ belong for $\mathrm{Fe}_{2} \mathrm{O}_{3}$ and other types of iron oxide nanoparticles [19].

\section{CONCLUSION}

The density of catalyst nanoparticles deposited depended mainly on salt concentration and speed of spin coating. The density of particles decreased away from the center to the edge of the wafer. The diameter of the carbon nanotubes was correlated to the size of clusters deposited. A higher catalyst loading also produces MWNTs at $750{ }^{\circ} \mathrm{C}$. A Raman peaks and XRD indicate the presence of some form of carbon because non availability pure function of MWCNTs. This result emphasizes the need to maintain on the purification CNTs in the study. 


\section{References}

[1] S. Iijima,"Helical Micronanotubles of Graghitic Carbon,” Nature, 354, 56, (1991).

[2] B. Adrian, H. Peter, N. Takeshi and D. Cees, "Logic circuits with carbon nanotube transistors," Science 294, 1317(2001).

[3] F. Elzbieta and B. Francois, "Electrochemical storage of energy in carbon nanotubes and nanostructured carbons," Carbon 40 (10), 1775 (2002).

[4] C. F. Chen, C. L. Lin and C. M. Wang, "Field emission properties of vertically aligned carbon nanotubes grown on bias-enhanced hydrogen plasma-pretreated $\mathrm{Cr}$ film," Thin Solid Films 444, 64 (1-2) (2003).

[5] L. Valentini, I. Armentano and J.M. Kenny, "Sensors for sub-ppm NO 2 gas detection based on carbon nanotube thin films," Appl. Phys. Lett. 82, 961(2003).

[6] R. H. Baughman, A. A. Zakhidov and W. A. de Heer, "Carbon nanotubes the route toward applications," Science 2, 297, 787(2002).

[7] C .Journet and P .Bernier, "Production of carbon nanotubes," App. Phys., 67,1(1998).

[8] A. Thess, R. Lee, P. Nikolacv, H. Dai, P. Petit, et.al., Crystalline Ropes of Metallic Nanotubes," Science, V.273, 483 (1996).

[9] S. Iijima and T. Ichihash, "Single-shell carbon nanotubes of 1-nm diameter," Nature 363, 609 (1993).

[10] E. Tracz, R. Scholz and T. Borowiecki, "High resolution microscopy study of the carbon despite morphology on nickel catalyst,” Appl. Catal. V.66, 133 (1990).

[11] V. S. Medhekar, "Growth of Carbon Nanotubes on Model and Supported Catalysts," PHD thesis, Worcester Polytechnic Institute (2004).

[12] Ch. J. Lee, J. Park and J. A. Yu, "Catalyst effect on carbon nanotubes synthesized by thermal chemical vapor deposition," Chemical Physics Letters 360, 250(2002).

[13] K. Liu, K. Jang, Ch. Feng, Z. Chen and Sh. Fan, "A growth mark method for studying growth mechanism of carbon nanotube arrays," carbon, V.43, 2850(2005).

[14] S. Musso, S. porro, M. Vinante, L. Vanzetti. R. Ploeger, M. Giorcelli, B. possetti, F. trotta, C. Pederzolli and A. Tagliaferro, "Modification of MWNTs obtained by thermal-CVD," Diamond and Related Materials,V.16, 1183(2007).

[15] D. Yang, F. Yang, J. Hu, J. Long, Ch. Wang, D. Fu, and Q. Ni, "Hydrophilic Multi-Walled Carbon Nanotube Decorated with Magnetite Nanoparticles as Lymphatic Targetd Drug Delivery Vehicles," chemical communication, issues29, (2009).

[16] Z. Qiao, J. Li, N. Zhao, Ch. Shi, Ph. Nash, "Graphitization and microstructure transformation of nanodiamond to onion-like carbon”, Scripta Materialia, 54, 225(2006).

[17] N. A. Buang, F. Fadil, Z. Abdul Majid and SH. SHhir, "Characteristic of Mild Acid Functionalized MWCNTs Towards High Dispersion With Low Structural Defects", Digest Journal of Nanomaterials and Biostructures, Vol.7, No.1, 33(2012).

[18] K. Nishimura, N. Okazaki, L. Pan and Y. Nakayama, "In Situ Study of Iron Catalysts for Carbon Nanotube Growth Using X-Ray Diffraction Analysis,'Japanese Journal of Applied Physics, Vol. 43, 471(2004).

[19] J. M. Marulanda, "Electronic Properties of Carbon Nanotubes," book, INTECH, (2011). 